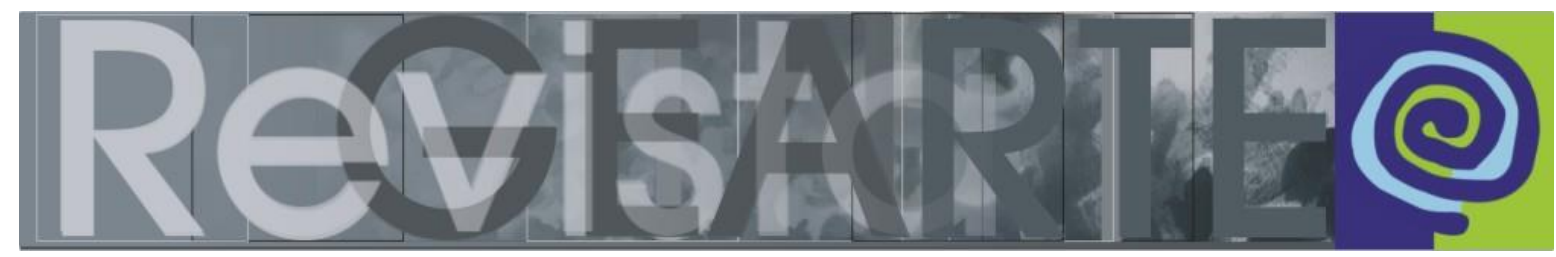

Volume 1, Número 1, Abril/2014, ISSN 2357-9854

\title{
Um breve histórico dos Fóruns de Pós-Graduação e de Graduação em Artes Visuais
}

\author{
Milton Sogabe (UNESP - Brasil)
}

\section{RESUMO}

O processo de organização do ensino de artes no Brasil, no contexto da academia, passa por diversas histórias recentes que se perdem, talvez por seus participantes estarem em atividade e termos a sensação de que o registro dos acontecimentos não é necessário ainda. Relatamos aqui pequena parte dessa história, esperando que essas informações contribuam para nossa reflexão. O Fórum de PósGraduação em Artes Visuais teve início em 2004 e o Fórum de Graduação aconteceu pela primeira vez em 2012.

\section{PALAVRAS-CHAVE}

Fórum de pós-graduação em artes visuais; Fórum de graduação em artes visuais; Ensino de artes

\section{ABSTRACT}

The process of organization of the teaching of Arts in Brazil in the context of the Academy passes through several recent stories that get lost. Maybe because its participants are active and have the feeling that the record of events is not necessary yet. We report here a small part of that history hoping that this information will contribute to our reflection. The Graduate Forum in Visual Arts began in 2004 and the Undergraduate Forum took place for the first time in 2012.

\section{KEYWORDS}

Graduate Forum in Visual Arts; Undergraduate Forum in Visual Arts; Art teaching.

\section{Pesquisa de arte na Academia}

No contexto brasileiro, a pesquisa de arte na Academia de forma mais sistematizada inicia-se com a implantação da pós-graduação em artes. Toda a mudança acontecida nas últimas três décadas transformou o artista-professor em pesquisador-artista, o ateliê de arte em laboratório de arte, a produção solitária em produção nos grupos de pesquisa, o mercado de arte pelas agências de fomento à pesquisa e editais de produção de obras, de residência artística, e de produção de eventos, a pasta com trabalhos embaixo do braço pela apresentação de projetos etc.

São inúmeras as mudanças que podemos notar no contexto da arte na Academia, quando o artista plástico, agora artista visual, dividia seu tempo entre 0 ateliê e o ensino na graduação.

Com a exigência do título de doutor para ingressar na vida acadêmica da docência, os compromissos do artista foram ampliando-se no contexto da consolidação da área de artes como área de conhecimento e pesquisa. Tanto as 
características do docente de arte modificaram-se, quanto o universo dos alunos da graduação. Atualmente, a partir do momento que o aluno ingressa na graduação ele tem tantas opções na sua formação, que é preciso ter um projeto de vida para decidir por onde caminhar. Os dois caminhos mais usuais são o do mercado de arte, como artista e o da educação, como professor, que podem se mesclar, além de outras atividades e áreas onde o egresso de arte pode atuar.

A complexidade atual da nossa realidade solicita indivíduos com formação com certa interdisciplinaridade para compreendê-la e vivenciá-la. Os bacharelados interdisciplinares já são uma realidade, e no contexto da pós-graduação notamos um dos maiores crescimentos na área interdisciplinar. A maioria dos cursos de graduação solicita que o aluno escolha parte das disciplinas e atividades para a sua formação. Durante a graduação os alunos encontram ofertas de intercâmbio internacionais, inúmeros editais de residências artísticas, editais para fomento à produção artística, programas de extensão, bolsas de estudo da universidade e das agências de fomento, além de outras ofertas das universidades no exterior que investem também na internacionalização. Porém, um problema que encontramos na graduação é que nossos alunos são na grande maioria monolíngue e não aproveitam essas oportunidades. Um projeto de ensino de idiomas seria necessário desde a graduação até a pós-graduação para superar essa barreira que impede a saída de nossos alunos para o exterior, seja para estudar ou participar de congressos.

Para o docente, os compromissos se ampliaram e não se restringem à sala de aula, pois como pesquisador precisa ter um grupo de pesquisa, participar de eventos científicos, buscar fomento para suas pesquisas, fazer parte da associação da sua área, realizar convênios com outras universidades, publicar suas pesquisas, dar pareceres para as agências de fomento, orientar pesquisas na graduação e pósgraduação, participar de bancas, além das atividades de extensão e gestão e para os artistas, produzir obras também. Embora não tenhamos nenhuma formação em gestão, essa atividade passou a fazer parte da vida do docente, que atua mais como "bombeiro" do que como gestor, não permitindo um bom desenvolvimento dos cursos. Com certeza, para um único docente realizar todas essas tarefas é impossível ou sobrecarrega-o provocando estresse, fato que está acontecendo com a maioria de nossos docentes. O que se faz necessário é pensarmos em grupo, dividir tarefas, nos 
organizarmos, para conseguirmos uma qualidade melhor nos nossos cursos, nas nossas atividades e nas nossas vidas. A organização se faz necessária, não só no corpo docente do curso, mas em outros níveis mais amplos, dos cursos de graduação e pós-graduação.

\section{Fórum de Graduação}

Ainda não possuímos uma organização dos cursos de graduação em cada área de conhecimento, no sentido de que eles se reúnam, discutam seus problemas, troquem experiências e participem de uma construção coletiva do ensino em suas áreas.

As pró-reitorias de graduação possuem o ForGRAD (Fórum Nacional de PróReitores de Graduação), que trata de políticas mais amplas da educação superior. Encontramos poucas áreas que reúnem seus cursos de graduação de forma organizada, tal como a área de História, Química e Saúde Coletiva.

A graduação não possui as mesmas características da pós-graduação, no que diz respeito ao sistema de avaliação. O INEP, responsável pela avaliação do ensino superior, foi criado em 1937, chamado inicialmente de Instituto Nacional de Pedagogia, Instituto Nacional de Estudos Pedagógicos no ano seguinte e depois em 1972, Instituto Nacional de Estudos e Pesquisas Educacionais Anísio Teixeira. O INEP é responsável pela organização do sistema de avaliação dos cursos superiores do país, realizando o Exame Nacional de Desempenho de Estudantes (Enade) e as avaliações in loco realizadas pelas comissões de especialistas. O sistema de avaliação do INEP tem a função de avaliar os cursos para autorização, reconhecimento e renovação de reconhecimento (http://portal.inep.gov.br).

Existe um sistema de cursos de graduação no país, mas este sistema não está materializado de fato pelos seus coordenadores, que não têm contato entre si e desconhecem o que acontece em outros cursos do país. A ideia de um Fórum de Coordenadores de Curso de Graduação de Artes Visuais surge com o objetivo de possibilitar o encontro dos coordenadores para uma troca de experiências, discussão de problemas existentes na área e formulação de projetos coletivos para o desenvolvimento do ensino de artes visuais no país, que costumam ser construídos apenas em níveis mais fechados, sem consultas mais amplas. 
Antes do primeiro encontro nacional de coordenadores de graduação, o processo teve início com algumas reuniões de quatro cursos de graduação de São Paulo, relacionados aos programas de pós-graduação da UNESP, UNICAMP, USP e FASM (Faculdade Santa Marcelina). Apesar de os coordenadores serem amigos e se conhecerem por muito tempo, nunca haviam se reunido para conversarem sobre os cursos. As pessoas envolvidas nesse processo foram os coordenadores Silvia Laurentiz (USP), Edson Pfutzenreuter (UNICAMP), Mirtes Marins de Oliveira (Faculdade Santa Marcelina), Rosangela Leote (vice-coordenadora em exercício da UNESP) e Milton Sogabe (UNESP) como propositor do fórum.

Durante o ano de 2001 as reuniões foram realizadas para discutir vários aspectos dos cursos, resultando em trocas de experiências que muito contribuíram para o planejamento de cada curso. Durante o percurso aconteceu do curso de pósgraduação da faculdade Santa Marcelina fechar o processo seletivo, finalizando o mestrado. No final foi redigida uma carta para a ANPAP propondo a realização de uma reunião nacional de coordenadores de graduação, de cursos relacionados aos programas de pós-graduação. A proposta de criação do Fórum de Graduação em Artes Visuais foi levada para a Assembléia da ANPAP em 2011, sendo aprovada e programada para acontecer em setembro de 2012, em Niterói (RJ), durante o $21^{\circ}$ Encontro Nacional da ANPAP.

A proposta de um Fórum de Graduação já está presente com o surgimento do Fórum da Pós-Graduação. Logo nas primeiras reuniões do Fórum de Pós-Graduação, encontramos esta proposta registrada em ata:

\footnotetext{
O prof. Milton sugeriu que fosse levado para a assembleia geral da ANPAP a criação de um Núcleo da Graduação, da mesma maneira como havia sido construído o Núcleo de Pós-Graduação, justificando que a ANPAP já desenvolvia um excelente trabalho de mapeamento e publicação anual das pesquisas em artes visuais, mas que a pesquisa deveria ser trabalhada não só no seu produto final, a publicação, mas em todo o seu processo desde a graduação (Ata do fórum de pós-graduação na ANPAP, 2004).
}

O critério inicial para a participação no fórum de graduação levou em consideração o contexto da ANPAP, uma associação de pesquisadores. Espelhado no Fórum de Pós-Graduação, foram convidados cursos relacionados aos programas de pós-graduação stricto sensu em Artes, reconhecidos pela CAPES, com o intuito de 
discutir e promover a pesquisa na graduação, relacionada com a pesquisa na pósgraduação, como partes de um mesmo sistema.

A reunião aconteceu no Solar do Jambeiro, em Niterói, concomitantemente com a reunião do fórum de coordenadores de pós-graduação, que já acontece desde 2003. O coordenador (2011-2012) do Fórum de Pós-Graduação, Luiz Sérgio de Oliveira (UFF), organizou a infraestrutura para realização dos dois fóruns no mesmo local, visando um momento em conjunto.

Para esse primeiro encontro foram convidadas 19 instituições, envolvendo 38 cursos e compareceram 14 instituições, num total de 20 coordenadores de curso. $O$ Fórum de Graduação possibilitou pela primeira vez um contato entre os coordenadores de curso, que nos dois dias apresentaram seus cursos e tiveram uma fotografia do ensino de Artes Visuais no país.

Além das especificidades locais, que contextualizam os projetos políticos pedagógicos de cada curso, constatamos na maioria dos cursos alguns pontos em comum, tais como as atividades extracurriculares e disciplinas optativas no curso e eletivas na universidade, que apontam para uma autonomia de escolhas na formação de cada indivíduo. A questão da interdisciplinaridade parece penetrar e se fazer necessária cada vez mais na formação dos profissionais de todas as áreas, frente à complexidade atual de nossa realidade. A utilização das TIC (Tecnologias da Informação e Comunicação), permitidas em até $20 \%$ da carga horária total da disciplina (Portaria nำ4.059, de 10 de dezembro de 2004, que regulamenta o artigo 81 da Lei de Diretrizes e Bases da Educação - 9394/96), ainda parece inexistente na maioria dos cursos, embora já tenhamos curso de Licenciatura em Artes Visuais da UAB - Universidade Aberta do Brasil, que é um sistema integrado por universidades públicas para oferecimento de cursos para uma população com dificuldade de acesso ao nível superior, utilizando a educação à distância, conforme nos apresentou a coordenadora Ana Beatriz Barroso (UnB). A Diretoria de Educação a Distância (DED) da Coordenação de Aperfeiçoamento de Pessoal de Nível Superior (Capes) que coordena a UAB divulgou uma portaria em 05 de dezembro de 2012, instituindo a formação de um Fórum Nacional de Coordenadores do Sistema Universidade Aberta do Brasil - UAB "para apoiar e subsidiar a CAPES na formulação de diretrizes, 
definição de critérios técnicos e pedagógicos, parâmetros e demais ações no âmbito do Sistema UAB" (http://www.uab.capes.gov.br).

Embora várias questões tivessem surgido, e sido discutidas rapidamente, a primeira reunião só permitiu que os cursos se apresentassem, não possibilitando tempo para a discussão dessas questões. De toda maneira, o processo deu início a uma nova etapa para a graduação, que nas próximas reuniões poderá trocar experiências e discutir várias questões, sem pretender atingir uma homogeneização nas propostas curriculares, pois a diversidade parece ser a riqueza da área.

Algumas instituições já permitem que alunos de iniciação científica frequentem disciplinas na pós-graduação, validando os créditos na graduação, fato que insere o aluno com características de pesquisador no ambiente da pós-graduação. Essa inserção foi lembrada no contexto do ensino médio também, com a existência de bolsa de estudo para Iniciação Científica Jr, onde alunos do segundo ano do ensino médio ganham bolsa para participar de uma pesquisa na universidade. A preparação do pesquisador pode se iniciar desde o ensino médio, com sua manifestação de interesse.

A maioria dos coordenadores apontou falta de infraestrutura física para os seus cursos, que parece ser um ponto em comum em todos os cursos.

A dificuldade do ensino de arte contemporânea também foi um fato recorrente em vários cursos. Embora algumas instituições tenham espaços culturais como museus e galerias, estes espaços colocaram-se como essenciais para a formação dos alunos de graduação em artes visuais, comparando-se à importância dos hospitais para os cursos de medicina. A falta de técnicos para os laboratórios nesses espaços culturais foi outro problema apontado em vários cursos. Nesses espaços os alunos vivenciam vários processos de aprendizagem, que vão desde a curadoria até a montagem de exposições, passando por exposição de suas obras, prática de mediação com o público, oferecimento de workshops e vivência com artistas convidados.

Percebemos que as 400h de Prática de Ensino são interpretadas e inseridas no currículo de várias maneiras, não havendo uma única solução até o momento. 
Enfim, destacamos apenas algumas questões, que o fórum terá de organizar para discussão nos próximos encontros.

\section{Fórum de pós-graduação em artes visuais}

A pós-graduação em artes no Brasil tem início em 1974, na ECA-USP, com o mestrado e em 1980 o doutorado. Até o ano 2000 tínhamos 17 programas de pósgraduação na área de artes, envolvendo as três subáreas, e em 2012, chegamos a 43 programas, além de dois mestrados profissionais, que começam a surgir. Ao mesmo tempo que verificamos um crescimento, abrangendo quase todo o país, a área ainda está se organizando em vários aspectos desse novo contexto. Nesse período, desde o surgimento da pós-graduação, e da entrada da arte no sistema da pesquisa acadêmica, muitas transformações vêm ocorrendo. $O$ artista-professor passou a ser um pesquisador-artista, os ateliês passaram a ser denominados de laboratórios de arte, a prática da pesquisa e do trabalho individual mudou-se para o trabalho em grupos de pesquisa, e os compromissos dentro da Academia ampliaram-se para outras atividades além do ensino, envolvendo a extensão, a pesquisa e a gestão também (SOGABE, 2010).

A entrada da arte nesse sistema de pesquisa na Academia solicita novas organizações, com discussões de todos os envolvidos, para que a área consiga se consolidar. O Fórum de Pós-Graduação em Artes Visuais na ANPAP surge como uma dessas necessidades.

Ele é composto pelos coordenadores de programas de pós-graduação stricto sensu, de Artes Visuais e de Artes que são programas mistos que incluem artes visuais e/ou artes cênicas e/ou música, reconhecidos pela CAPES. Sua história tem origem em outra associação denominada ANPPAV - Associação Nacional de Pesquisa e Pós-Graduação em Artes Visuais, fundada em 1997.

A ANPPAV realizou três encontros, sendo o primeiro em 1997, no Rio e Janeiro, o segundo em 1999, e o terceiro em 2001, ambos em Salvador. O segundo encontro gerou os Anais, com o título "Artes Visuais - pesquisa hoje", organizado por Maria Celeste de Almeida Wanner, e publicado em 2001. Nesse período foram presidentes, primeiro Maria Amélia Bulhões(UFRGS) e depois Maria Celeste de Almeida Wanner(UFBA). 
Em 2001, quando participamos do terceiro encontro em Salvador, na UFBA (Universidade Federal da Bahia), detectamos que a associação estava com alguns problemas legais, pois não tinha a documentação regularizada; a última diretoria não estava registrada; não possuia CNPJ, conta no banco ou um endereço no registro de fundação. Após algumas consultas nos órgãos envolvidos no processo para registro de associações, chegamos à conclusão de que teríamos de reiniciar todo o processo, como se fundássemos uma nova associação. Apresentamos algumas possibilidades e uma delas era realizar os encontros dentro da ANPAP - Associação Nacional de Pesquisadores em Artes Plásticas, sem necessidades burocráticas para regularização da ANPPAV e aproveitando um evento, do qual a maioria dos coordenadores costumava participar. Em 2002, levamos a proposta para a ANPAP, cuja presidente na época era Maria Beatriz Medeiros, que aprovou a realização da reunião e em 2003 aconteceu o primeiro encontro dos coordenadores de pós-graduação dentro do $12^{\circ}$ Encontro Nacional da ANPAP, que aconteceu em Brasília.

A área de Música já possuía a ANPPOM - Associação Nacional de Pesquisa e Pós-Graduação em Música, desde 1988 e a área de Artes Cênicas possuía a ABRACE- Associação Brasileira de Pesquisa e Pós-Graduação em Artes Cênicas desde 1998, sendo que em ambas as associações os coordenadores de pósgraduação se reuniam.

As quatro primeiras reuniões do Fórum de Pós-Graduação em Artes Visuais aconteceram em 2003 (Brasília), em 2004 (Brasília), em 2005 (Goiânia) e em 2006 (Salvador) e foram coordenadas por Milton Sogabe (UNESP). Depois a coordenação do fórum passou a seguir o período de dois anos, como o das gestões da ANPAP, assumindo a coordenação Sandra Rey (UFRGS/2007-2008), cujas reuniões aconteceram em Florianópolis, na UDESC. Depois de Sandra Rey, a coordenação passou para Maria Herminia Olivera Hernández (UFBA/2009-2010), cujas reuniões aconteceram em Salvador e Cachoeira, na Bahia. Na gestão de 2011-2012 a coordenação ficou sob a responsabilidade de Luiz Sérgio de Oliveira (UFF) e as reuniões aconteceram em Niterói (RJ), passando a coordenação em 2013-2014 para Mauricius Farina (UNICAMP).

As primeiras reuniões caracterizaram-se por muito desconhecimento do sistema de avaliação da pós-graduação na CAPES, gerando muitas dúvidas sobre os 
critérios de avaliação e das atividades existentes em cada programa, uma vez que os coordenadores nunca haviam se reunido para se conhecerem ou discutirem os problemas em comum. Nessas reuniões também começaram a discutir e organizar coletivamente as indicações para envio da lista tríplice para candidato à coordenação da área de Artes/Música na CAPES.

Em 2005 a CAPES iniciou uma nova orientação, quando estavam coordenação da área de Artes/Música, Martha Tupinambá de Ulhôa (UNIRIO/Música) e a coordenadora adjunta Maria Beatriz Medeiros (UnB/Visuais), organizando uma reunião anual com os coordenadores de programas de pós-graduação na sede da CAPES em Brasília, para discussão dos critérios de avaliação e outras questões relacionadas à Pós-Graduação. Esse processo desencadeou um conhecimento maior sobre os critérios de avaliação e uma discussão por comissões específicas convidadas pela coordenação de área. As reuniões dos coordenadores possibilitavam uma troca de experiências e discussões provocando um desenvolvimento dos programas de pós-graduação em artes no Brasil, através de um trabalho conjunto. Com as três sub-áreas organizando as reuniões de coordenadores de pós-graduação em suas associações e as reuniões anuais de todos na CAPES, podemos considerar que a pós-graduação e a pesquisa em Artes no Brasil iniciou uma nova etapa. Nessa fase a produção artística passou a ser avaliada, conforme a área toda vinha solicitando para que fosse considerada, com a mesma importância da produção bibliográfica. Uma comissão composta por docentes da pós-graduação iniciou a discussão e construção de um instrumento para avaliar a produção artística, representando a realização de um desejo da área, conseguida coletivamente. Nesse sentido os critérios de avaliação são discutidos e construídos pelos próprios docentes dos programas de pós-graduação da área que, fazendo parte de comissões montadas pela coordenação de área, após consultar os programas, se reúnem, discutem os critérios e avaliam a produção da área.

Nas últimas reuniões do fórum de pós-graduação na ANPAP, percebemos uma grande mudança e progresso desde as primeiras reuniões, demonstrando não só um maior conhecimento dos critérios de avaliação, mas construindo esses critérios coletivamente. 
A presença dos vice-coordenadores no fórum também foi um fator relevante para a continuidade do processo, não possibilitando que uma troca grande de coordenadores pudesse retroceder a discussão e todo o trabalho construído.

Em 2011, a avaliação continuada realizada pela CAPES - que habitualmente era constituída por uma comissão com dois representantes de cada área, que enviavam para o programa um relatório escrito sobre a avaliação - transformou-se em um Seminário de Avaliação Continuada, com presença de todos os coordenadores apresentando uma autoavaliação de seus programas. A área de artes realizou seu primeiro Seminário de Acompanhamento em fevereiro de 2012 e o segundo em novembro de 2012, sob a coordenação da área de Artes/Música na CAPES, de Antonia Pereira Bezerra (UFBA/Cênicas) e coordenação adjunta de Milton Sogabe (UNESP/Visuais), no período de 2011 a 2014. Essa mudança passou de um processo de recepção de uma avaliação por escrito de uma comissão, para uma reunião presencial, com todos os coordenadores apresentando seus programas com aspectos positivos e metas a cumprir, possibilitando uma troca de experiências e uma autocrítica dos programas. Nessa convivência, vários projetos surgiram para o desenvolvimento da área de artes no contexto da pesquisa.

Uma delas foi o projeto de Martha Ulhôa, de uma publicação de qualidade para toda a área de artes, que foi viabilizada pela coordenadora de área Antonia Pereira Bezerra, em novembro de 2012, com a organização de um evento para a implantação de um Journal Reseach of Arts, bilíngue, com abrangência internacional. Com a proposta da CAPES, para financiamento de dois periódicos por área, a coordenadora Antonia Bezerra, para não privilegiar nenhuma das sub-áreas de artes, consultou Martha Ulhôa sobre o projeto do Journal, que confirmou o desejo de levar o projeto adiante. Bezerra conseguiu patrocínio para um evento de organização do Journal, que aconteceu em Natal, na UFRN, instituição que acolheu e patrocinou grande parte do evento. Durante uma semana foram apresentados trabalhos de 15 pesquisadores indicados pelas associações, além de cinco estrangeiros e realizadas reuniões para definição do Journal, que ficaria sob a responsabilidade das associações. Este fato representou mais um avanço da pesquisa em artes no país.

Nesse mesmo período acontecia o debate do mestrado profissional na área de artes. 
$\mathrm{Na}$ reunião anual de coordenadores dos programas de pós-graduação em artes, em fevereiro de 2012, na CAPES, em Brasília, foi apresentado o mestrado profissional, já com a existência de 380 mestrados profissionais no sistema de pósgraduação no país (BEZERRA, 2012). A área de artes recebeu com muita resistência o mestrado profissional colocando questões em choque com o mestrado acadêmico. Mas aos poucos a discussão e os esclarecimentos foram acontecendo e a percepção de que a formação de pessoas qualificadas na área de artes, em nível de pósgraduação, não se restringia ao mundo acadêmico, mas também às várias funções que o artista desenvolve no mundo externo à Academia, em vários setores da sociedade.

Em março de 2012 aconteceu uma reunião organizada pelos programas de pós-gradução em artes da UFBA, com a presença do diretor de avaliação da CAPES, prof. Livio Amaral, que apresentou um histórico e esclareceu várias dúvidas, com presença dos presidentes de associações da área de artes e alguns coordenadores interessados no assunto.

Surgiram no mesmo ano propostas de mestrado profissional em Música da UFBA, com coordenação do prof. Lucas Robatto e mestrado profissional em Ensino de Artes Cênicas da UNIRIO, com coord. do prof. Paulo Merisio, que foram aprovados e tiveram início em 2013. Iniciou-se também a discussão e organização de um mestrado profissional para ensino de artes em rede nacional, semelhante ao PROFMAT (ensino de Matemática) e PROFLETRAS (ensino de Letras), que já aconteciam em rede nacional.

Em 2013 foi aprovado a proposta do PROFARTES, para formação de professores da Educação Básica do ensino de Artes, com participação inicial de 13 instituições de ensino em rede nacional, com coordenação do prof. André Carreira da UDESC, com início em 2014, inaugurando uma nova fase do ensino de artes no país.

\section{Referências}

ABRACE. Associação Brasileira de Pesquisa e Pós-Graduação em Artes Cênicas. Disponível em <http://portalabrace.org >. Acesso em 12 out. 2012.

ANPAP. Associação Nacional de Pesquisadores em Artes Plásticas. Espaço histórico. Disponível em <http://www.anpap.org.br>. Acesso em 07 dez. 2012. 
ANPPOM. Associação Nacional de Pesquisa e Pós-Graduação em Música. Disponível em: <http://www.anppom.com.br>. Acesso em 23 out. 2012.

BEZERRA, Antonia Pereira. Relatório da reunião de coordenadores dos programas de pós-graduação em Artes/Música. CAPES. Brasília, 2012. Disponível em: <http://www.capes.gov.br/images/stories/ download/avaliacao/Relatorio_Reuniao_Coordenadores_Artes_Musica.pdf >. Acesso em 14 ago. 2013.

BRASIL. Coordenação de Aperfeiçoamento de Pessoal de Nível Superior - CAPES. Portaria $n^{\circ} 170$, de 5 de dezembro de 2012 - Institui Fórum Nacional de Coordenadores do Sistema Universidade Aberta do Brasil - UAB e dá outras providências. Diário Oficial da União. 끈 236, sexta-feira, 7 de dezembro de 2012, Seção 1. p. 40. Disponível em: <http://www.capes.gov.br/images/stories/download/legislacao/ Portaria170-5dez2012-UAB.pdf>. Acesso em 10 ago. 2013.

FLEXOR, Maria Helena Ochi. A historiografia da arte baiana na contemporaneidade. In: XXIV Colóquio do CBHA, 2004, Belo Horizonte/MG. Anais... Belo Horizonte, 2004. Disponível em: <http://www.cbha. art.br/coloquios/2004/textos/74_maria_helena_flexor.pdf>. Acesso em 10 ago. 2013.

FÓRUM DOS COORDENADORES DOS CURSOS DE PÓS-GRADUAÇÃO EM ARTES VISUAIS. Ata de 2010. Salvador. Disponível em: <http://www.anpap.org.br/documentos/ata_reuniao_forum_ 2010.pdf>. Acesso em: 17 jul. 2013.

INEP. História do Inep. Disponível em: <http://portal.inep.gov.br/institucional-historia>. Acesso em: 12 dez. 2013.

SOGABE, Milton. O ensino de artes e a formação do artista na academia. In: Marcelina: Revista do Mestrado em Artes Visuais da Faculdade Santa Marcelina, São Paulo, v. 4, ano 3, 2010.

UAB - Universidade Aberta do Brasil. Criado Fórum Nacional de Coordenadores do Sistema Universidade Aberta do Brasil. Disponível em: <http://www.uab.capes.gov.br/index.php?option= com_content\&view=article\&id=219:criado-forum-nacional-de-coordenadores-do-sistema-universidadeaberta-do-brasil-\&catid=1:noticia\&ltemid=7>. Acesso em 21 jun. 2013.

WANNER, Maria Celeste de Almeida (Org.). Artes Visuais: Pesquisa Hoje. In: ENCONTRO DA ASSOCIAÇÃO NACIONAL DE PESQUISA E PÓS-GRADUAÇÃO EM ARTES VISUAIS, 2., 2001, Salvador/BA. Anais... Salvador/BA: ANPPAV, 2001.

\section{Milton Sogabe}

Mestrado e doutorado em Comunicação e Semiótica pela PUC-SP; docente da UNESP; bolsista em produtividade CNPq; associado da ANPAP; grupo de pesquisa cAt - ciência, arte, tecnologia; forma o SCIArts - Equipe Interdisciplinar; coordenador adjunto da área de Artes/Música na CAPES (20112013); propositor e organizador dos fóruns de pós-graduação (2003) e graduação (2012) na ANPAP.

E-mail-milton@ia.unesp.br

Currículo - http://lattes.cnpq.br/7600718608296628 